\title{
La evolución del uso del suelo y del agua en la cuenca del arroyo Piçarrão (Araguari-MG-Brasil): un estudio de caso ${ }^{1}$
}

\author{
Elizabete Oliveira Melo² y Manfred Fehr²
}

\begin{abstract}
RESUMEN
La expansión agrícola ocurrida en la cuenca del arroyo Piçarrão de 1970 a 2005 produjo mudanzas en el uso del suelo y del agua todavía no documentadas en la literatura. En este trabajo se hizo un diagnóstico de la situación existente en los años de 2002 a 2004 y se evaluaron las perspectivas de la actividad agrícola en la cuenca. Además, se efectuaron análisis de la literatura disponible, entrevistas con 16 productores rurales y trabajos de campo en el área del arroyo y de sus afluentes. Los resultados del estudio se presentan en forma de mapas y tablas. Se verificó que el área total drenada de la cuenca es de $388 \mathrm{~km}^{2}$, que la irrigación se procesa con nueve pivotes y que el caudal del arroyo fluctúa entre 1,5 y $80 \mathrm{~m}^{3} / \mathrm{s}$, con un promedio anual de $8 \mathrm{~m}^{3} / \mathrm{s}$. La disponibilidad de agua fue identificada como el principal factor límite para el desarrollo de la agricultura irrigada en la cuenca.
\end{abstract}

Palabras clave: Agricultura irrigada, Araguari, arroyo Piçarrão, expansión agrícola, uso del suelo y del agua.

\begin{abstract}
The agricultural expansion in the basin of the creek Piçarrão during the period from 1970 to 2005 produced changes in the use of soil and water that heretofore have not been documented in the literature. A diagnosis of the situation was carried out for the years 2002 to 2004 to evaluate the prospect of agricultural activity in the basin. The literature was reviewed, 16 rural producers were interviewed, and the creek and its tributaries were inspected. The results of the study are presented in form of maps and tables. The total area drained by the creek is $388 \mathrm{~km}^{2}$, nine pivots do the irrigation, and the creek's flow rate varies between 1.5 and $80.0 \mathrm{~m}^{3}$ per second with an annual average of $8.0 \mathrm{~m}^{3}$ per second. The study identified water availability as main limiting factor of agricultural development in the basin.
\end{abstract}

Key words: Irrigated agriculture, Araguari, Piçarrão creek, agricultural expansion, soil and water use.

La región de Araguari (Brasil), donde se encuentra el área de estudio, es una región de diversas prácticas económicas, debido a su riqueza hídrica, tanto subterránea como

1 Artículo recibido el 15 de noviembre de 2008 y aceptado el 12 de febrero de 2009. fluvial, necesaria para cualquier producción, así como por la geomorfología plana, que facilita la agricultura (Rosa, 1992). Con variadas actividades, tanto de subsistencia

\footnotetext{
Instituto de Geografía, Universidad Federal de Uberlandia (Brasil). E-mail: toribate@gmail.com; prosec22@yahoo.com
} 
como industriales de gran escala, todas coexistiendo en esa área, el impacto al medio ambiente es preocupante y lleva investigadores y estudiantes a desarrollar estudios que puedan minimizar los daños (IBGE, 1979; Ferreira, 2001).

La ciudad de Araguari utiliza el arroyo Piçarrão en varios aspectos, tanto para el turismo en función de su belleza, como también económicamente. La dinámica agrícola de la cuenca del Piçarrão es comandada por la expansión de la producción de granos, como el maíz, la soja y la actividad cafetera de base moderna con el uso de irrigación (Assunção, 2002; Pessôa 1999). Todos esos productos están fuertemente vinculados al sector agroindustrial. La intensidad de la explotación agrícola en la región varía de acuerdo con el tipo y técnica de cultivo, que van desde la extracción de vegetaciones naturales y florestas cultivadas, a las planta- ciones temporarias intensamente mecanizadas, consideradas las de mayor impacto en el medio ambiente (Martine y Garcia, 1987; Graziano, 1999).

Araguari se localiza en la mesorregión geográfica Triángulo Minero/Alto Paranaíba (Figura $\mathrm{N}^{0} 1$ ) y está delimitada por el río Paranaíba al norte (que la separa de la provincia de Goiás) y el río Araguari al sur en el sentido sureste-noroeste y, además, por las divisas con los municipios de Uberlandia y Tupaciguara, Cascalho Rico y Estrela do Sul, en toda la extensión este, y en el sudeste por el municipio de Indianópolis.

La cuenca del arroyo Piçarrão, que ocupa un área de $388 \mathrm{~km}^{2}$, se localiza en el municipio de Araguari, entre las coordenadas geográficas $18^{\circ} 37^{\prime} 53^{\prime \prime}$ y $18^{\circ} 53^{\prime} 04^{\prime \prime}$ de latitud Sur y $47^{\circ} 44^{\prime} 44^{\prime \prime}$ y $48^{\circ} 07^{\prime} 12^{\prime \prime}$ de longitud Oeste.

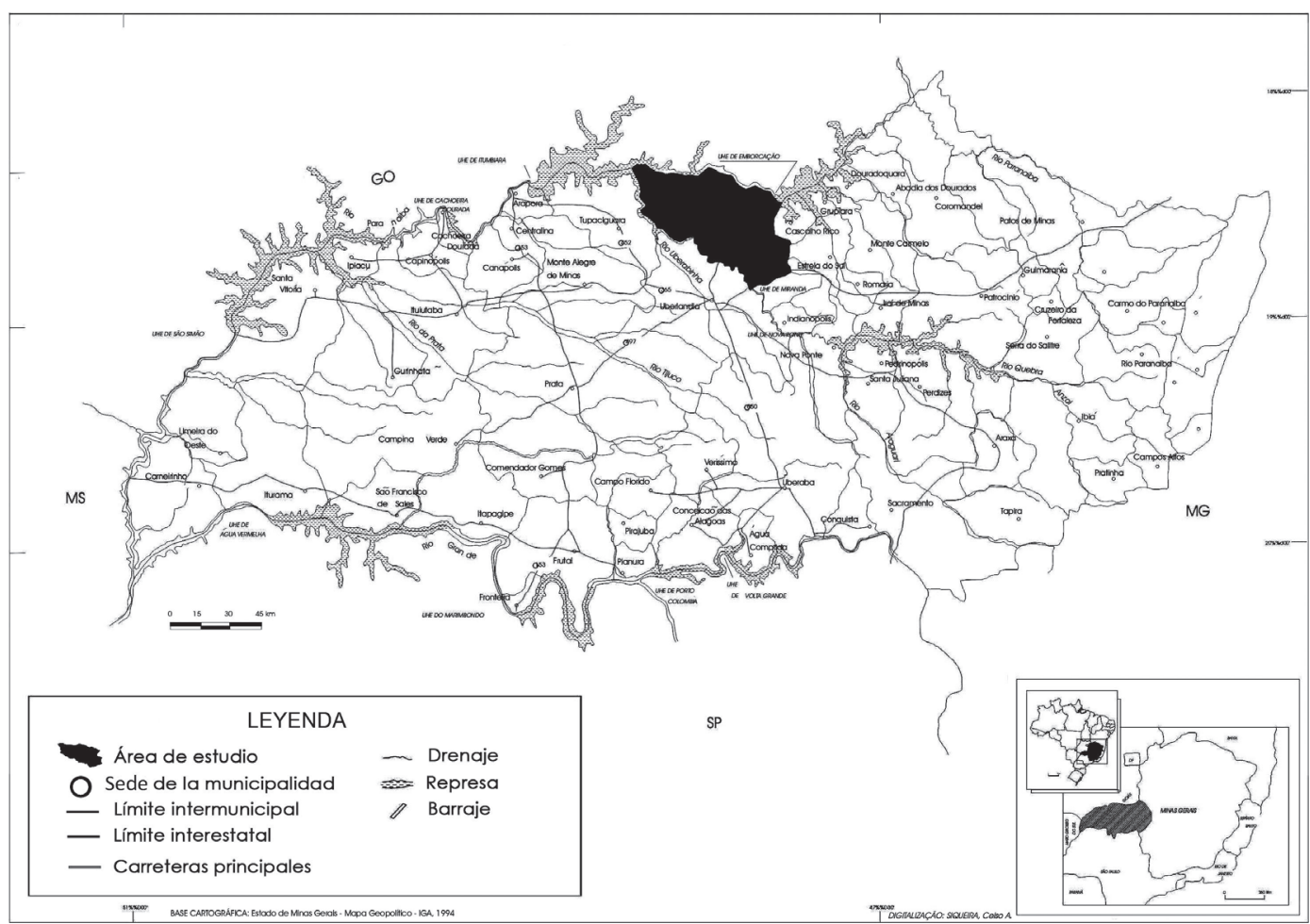

Fuente: Siqueira, 2005. 
El arroyo Piçarrão nace en el municipio de Estrela do Sul (MG) y es uno de los formadores del río Jordão. Su naciente está dentro de un área de reforestación que pertenece a una empresa especializada. Sus principales afluentes de margen derecha son: arroyo Lajeado, arroyo Arizona y arroyo Buriti Quebrado; de margen izquierda: arroyo Laguna Seca, arroyo Campo Alegre, arroyo Taboca, arroyo Estiva, arroyo Pindaítuba y arroyo Buriti Alto.

La investigación tuvo como objetivo acompañar por documentos existentes la evolución de la actividad agrícola en los últimos 30 años y obtener datos experimentales específicos sobre el uso del suelo y del agua para el período de 2002 a 2004, con la finalidad de evaluar las perspectivas de la actividad agrícola en la cuenca.

\section{Materiales y métodos}

El proceso de investigación para comprender las transformaciones ocurridas en el arroyo Piçarrão, a partir de la década del 70 , se estructuró en tres etapas.

La primera etapa fue desarrollada por estudios de literatura referentes al tema de la investigación, junto a las bibliotecas de la Universidad Federal de UberlandiaUFU; la Biblioteca Municipal de Araguari, por informaciones de órganos municipales; del Instituto Brasileño de Geografía Estadística-IBGE; de artículos, fuentes estadísticas y periódicos, con el objetivo de colectar informaciones que pudiesen auxiliar el análisis.

La segunda etapa se constituyó en la elaboración y digitalización del mapa de uso del suelo de la cuenca del Piçarrão. Toda esa parte técnica fue desarrollada en el Laboratorio de Geoprocesamiento de la Universidad Federal en el período de diciembre de 2004 a mayo de 2005. Para la preparación de los mapas de uso del suelo se utilizaron los siguientes materiales: cartas topográficas de la DSG (Directoria de los Servicios Geográficos del Ejército) del año de 1982 en la escala 1: 25.000, en una ampliación en la escala de 1: 15.500, e imágenes de satélite de los sensores
ETM+/LANDSAT 7 del 11/10/2002 y del sensor CCD/CBERS 2 del 8/9/2004 y del $30 / 5 / 2004$. Los softwares utilizados en esa etapa de investigación fueron: Cartalinx y Spring 4.1.

Con las imágenes obtenidas del Spring 4.1, fueron elaborados dos mapas de uso del suelo y de cobertura vegetal, uno para el año 2002 y otro para el año 2004.

A partir de esas cartas-imágenes fue posible identificar y delimitar las siguientes categorías: reforestación cortada, pastaje, mata ciliar, cerrado, cultura irrigada, cultura anual, cultura perenne, cuerpos de agua y campo hidrófilo.

En posesión de los dos mapas, se prosiguió con un análisis comparativo de los años de referencia principalmente sobre actividades agrícolas y, de una forma general, la evolución de la acción antropogénica dentro del área de la cuenca. Resultó también una tabla con la representación porcentual de cada categoría de uso en los años 2002 y 2004, que facilita la interpretación de los resultados de la clasificación de la imagen (Cuadro $N^{0} 1$ ).

La tercera etapa del proceso, la investigación de campo, fue realizada en varias fases. En un primer momento fue hecha una visita general a los puntos más relevantes de la cuenca del Piçarrão, donde se tomaron fotografías y se colectó información en diversos puntos del área de estudio.

El paso siguiente fue la elaboración del guión de entrevista, el cual fue testado en visitas de averiguación, realizadas en una de las haciendas. A partir de esas visitas se reestructuró el guión de entrevistas y se definió la muestra, a saber, 16 productores (pequeños, medios y grandes). El número propuesto representa $32 \%$ del universo de los productores de la cuenca.

En posesión de tal información, se comenzó con la sistematización de los datos en tablas y figuras y con la organización del material fotográfico obtenido en el campo. 


\section{Resultados y discusión}

\section{El proceso de modernización agrícola en la cuenca}

De acuerdo con los datos obtenidos a partir de las entrevistas realizadas con los 16 productores de la cuenca, se observa que en 1980 el principal producto cultivado en la región era el café. Según los entrevistados, con el estancamiento del precio del café en el mercado internacional, el proceso de diversificación fue retomado e hizo que se buscasen alternativas económicas a la producción cafetera, destacando las culturas de soja y maíz. Además, hubo una tendencia a la modernización del sector, con la utilización de prácticas más adecuadas en todas las etapas del proceso productivo, la utilización más intensa de nuevas tecnologías y la preocupación constante por la calidad y la reducción de los costos; también existe la necesidad de adecuar las potencialidades naturales del suelo al plantío, por medio del análisis químico realizado por la totalidad de los productores, y de la corrección del suelo realizada en $87,5 \%$ de los establecimientos. La fertilización es otra práctica también adoptada en $87,5 \%$ de los establecimientos investigados.

"El uso intensivo de fertilizantes químicos se presenta como la forma más fácil, sin embargo, no sea la más indicada ni la más barata. En el período de euforia, durante la década del 70, hubo exceso de esta práctica que llegó a amenazar la propia estructura del suelo" (BRUM, 1987: 87). En lo que se refiere al uso de maquinarias, se constató que $100 \%$ de los entrevistados poseen maquinaria propia: $93,75 \%$ de ellos poseen tractor, $62,5 \%$ poseen cosechadoras y $62,5 \%$ poseen otro tipo de equipamiento.

En cuanto a la asistencia técnica, apenas $18,75 \%$ de los productores entrevistados declararon no contar con la misma por ser agrónomos. La asistencia técnica es hecha por visitas que ocurren de acuerdo con la necesidad del productor ( $100 \%$ de los casos) y es constituida por visitas semanales $(37,5 \%$ de los casos) y diarias $(25 \%$ de los casos).
Una gran cantidad de dinero fue puesto a la disposición de los productores rurales, en la medida en que la modernización de la agricultura avanzaba (Chagas, 2002; Cunha, 1994). El crédito estaba disponible para todas las etapas del proceso productivo; "el crédito fácil y barato fue el principal factor del proceso de modernización de la agricultura" (BRUM, 1987: 120).

\section{El uso del suelo y del agua en los años 2002 y 2004}

Los mapas de uso del suelo fueron construidos a partir de imágenes del año 2002 (Figura $N^{\circ}$ 2) y 2004 (Figura $N^{\circ} 3$ ). Fueron encontradas las clases de: reforestación, reforestación cortada, cultura anual, cultura perenne, cultura irrigada, pastaje, mata, mata ciliar, campo hidrófilo, cuerpos de agua y cerrado. Esas clases sufrieron algunas modificaciones en cuanto a la extensión, forma y cantidad, y no son perceptibles con la simple observación del mapa. Sin embargo, por medio de cálculos de área (en hectáreas) generados en el programa Spring 4.1, fue posible tabular esos datos y generar el Cuadro $\mathrm{N}^{\circ} 1$ para expresar los resultados en porcentaje.

En el Cuadro $N^{0} 1$ se verifica el uso del suelo de la cuenca del arroyo Piçarrão en los años 2002 y 2004. Se observa que en el año 2002 la reforestación representó 33,7\%, la reforestación cortada $3,8 \%$, la cultura anual $32,7 \%$, la cultura perenne $2,0 \%$, la cultura irrigada $1,1 \%$, el pastaje $0,8 \%$, la mata $0,3 \%$, la mata ciliar $2,6 \%$, el campo hidrófilo 22,5\%, los cuerpos de agua $0,1 \%$ y el cerrado $0,4 \%$.

Ya en el año 2004 los resultados encontrados fueron: reforestación 37,6\%, reforestación cortada 1,9\%, cultura anual 29,7\%, cultura perenne 3,3\%, cultura irrigada 1,5\%, pastaje $1,89 \%$, mata $0,8 \%$, mata ciliar 2,2\%, campo hidrófilo $21,0 \%$, cuerpos de agua $0,01 \%$ y cerrado $0,1 \%$.

Los mapas producidos revelaron que la producción agrícola es intensa y bien variada, a pesar de que la mayor área está ocupada por reforestación perteneciente a la empresa especializada. Después de esa clase 
Cuadro $\mathrm{N}^{\circ} 1$

Distribución de los usos del suelo en la cuenca - años 2002 y 2004

\begin{tabular}{|l|r|r|r|r|}
\hline \multicolumn{1}{|c|}{ Usos } & Mapa 2004 (ha) & Fracción & Mapa 2002 (ha) & Fracción \\
\hline Reforestación & $14.631,5$ & 0,376 & $13.086,7$ & 0,337 \\
Reforestación cortada & 725,8 & 0,019 & $1.477,8$ & 0,038 \\
Cultura anual & $11.563,2$ & 0,297 & $12.685,0$ & 0,327 \\
Cultura perenne & $1.266,8$ & 0,033 & 765,5 & 0,020 \\
Cultura irrigada & 569,0 & 0,015 & 434,0 & 0,011 \\
Pastaje & 695,5 & 0,018 & 329,6 & 0,008 \\
Mata & 304,4 & 0,008 & 124,2 & 0,003 \\
Mata ciliar & 844,1 & 0,022 & $1.009,7$ & 0,026 \\
Campo hidrófilo & $8.155,9$ & 0,210 & $8.748,1$ & 0,225 \\
Cuerpos de agua & 24,4 & 0,001 & 29,0 & 0,001 \\
Cerrado & 57,1 & 0,001 & 148,1 & 0,004 \\
Total & $38.837,7$ & 1,000 & $38.837,7$ & 1,000 \\
\hline
\end{tabular}

Fuente: Elaboración propia.

Figura $\mathrm{N}^{\circ} 2$

Mapa de uso del suelo en la cuenca - año 2002

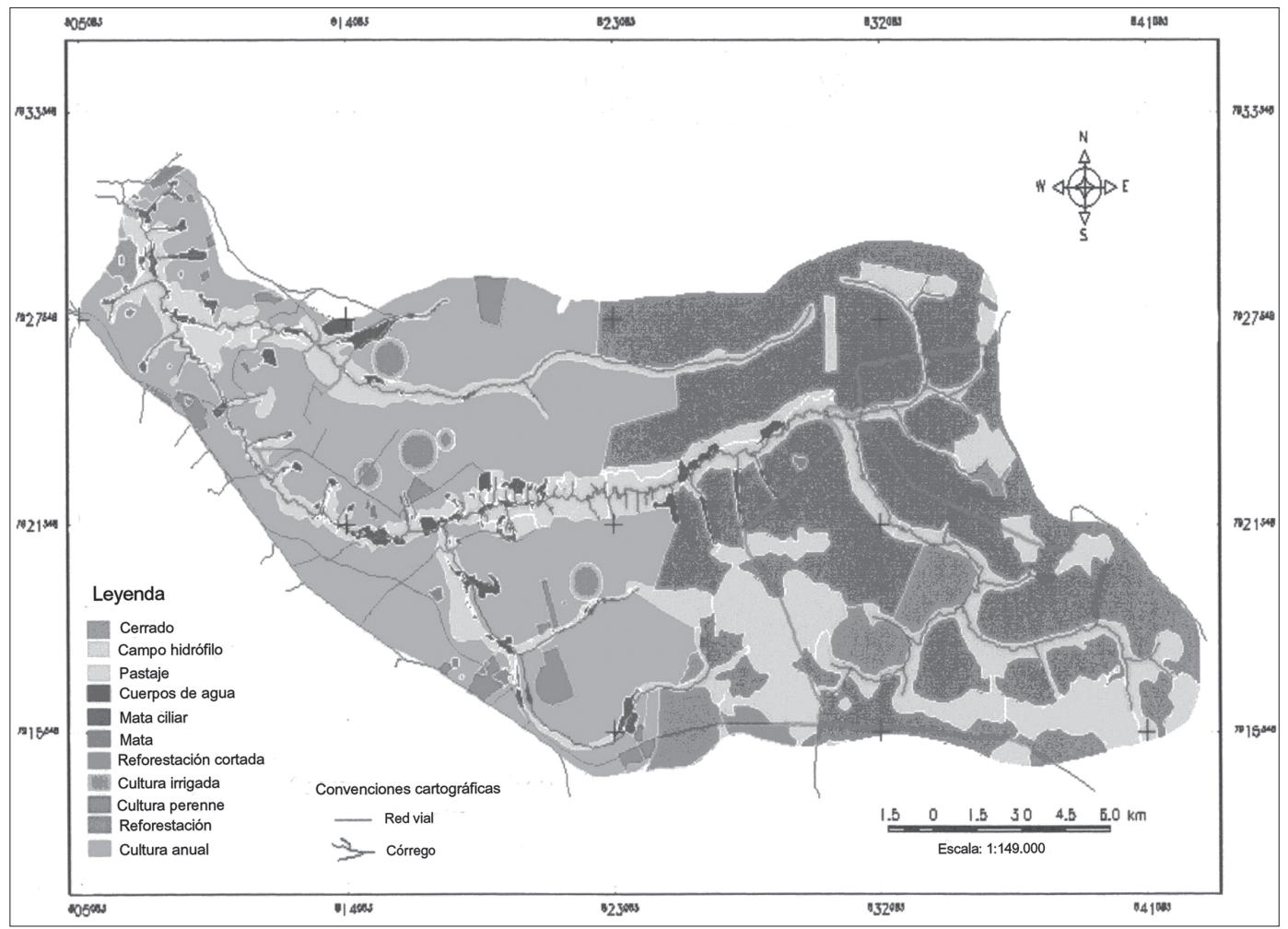

Fuente: Giffoni, 2005a. 
Figura $\mathrm{N}^{\circ} 3$

Mapa de uso del suelo en la cuenca - año 2004

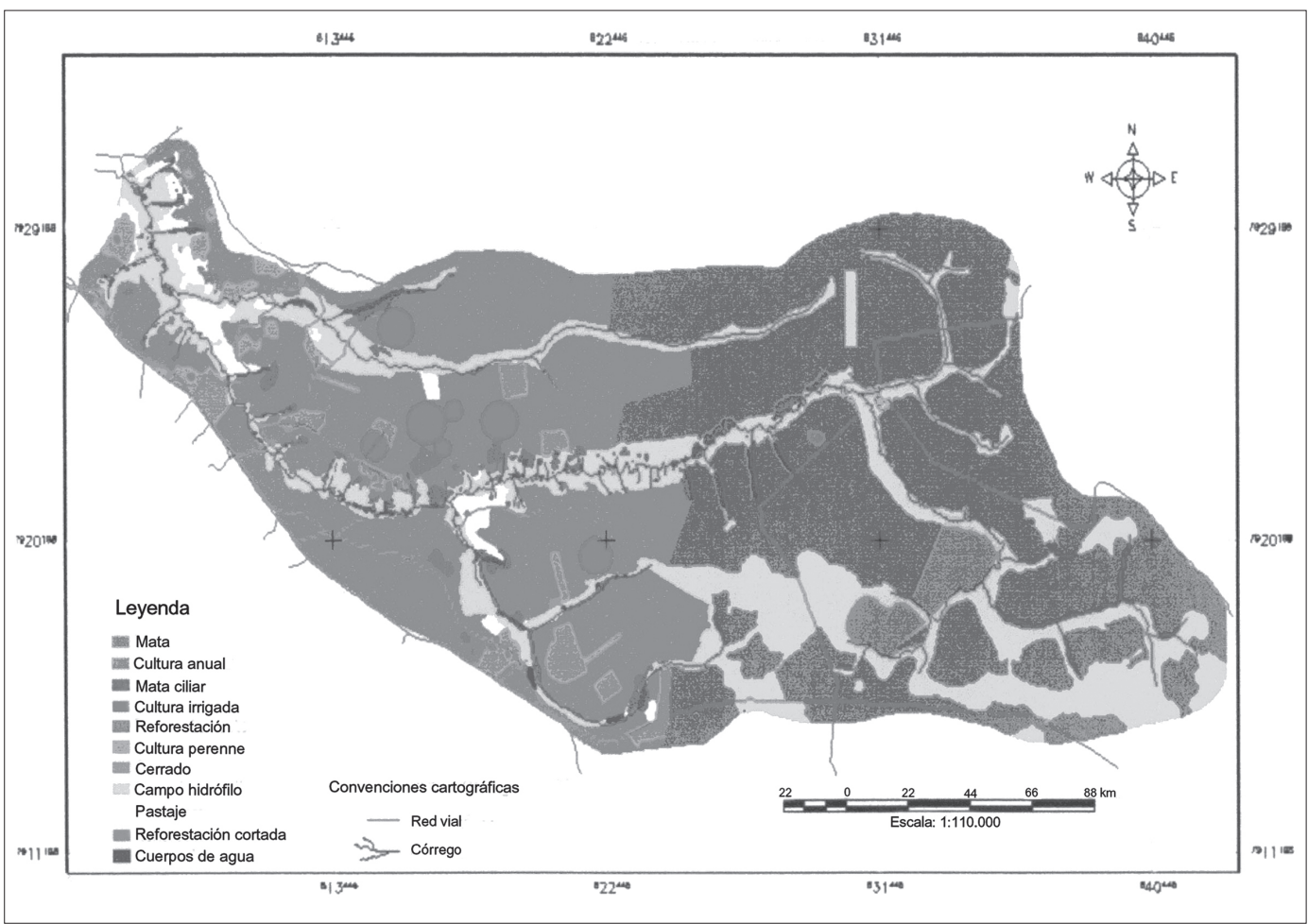

Fuente: Giffoni, 2005b.

de uso, la que más se destaca en tamaño es la cultura anual, principalmente de soja, que en algunos sitios se prolonga hasta el margen del arroyo Piçarrão.

Las clases de menor tamaño son los cuerpos de agua y la cobertura vegetal del cerrado. Esta última aun disminuyó entre 2002 y 2004, lo que es un factor preocupante, una vez que ella era la vegetación dominante originalmente.

Una parcela de reforestación, cortada en 2002, presentaba en el año 2004 especies de gran tamaño. En medio de esa gran parte cubierta por reforestación está la clase de campo hidrófilo, común principalmente en las márgenes de los cuerpos de agua y en las áreas húmedas.

La cultura anual disminuyó más; en contraste, la mecanización de las plantaciones se mostró fuerte con la introducción de pivotes, lo que hizo aumentar el porcentaje de la cultura irrigada (Cuadro $N^{0} 1$ ). La cultura perenne también ocupó el lugar de lo que antes era cultura anual, aumentando su porcentaje en 2004.

El pastaje también presentó mudanzas, aumentando de tamaño y tomando el lugar de algunas áreas de mata ciliar. Eso se configura como un dato alarmante, pues está destruyendo Áreas de Preservación Permanente del Arroyo. Las áreas de campo hidrófilo y mata tuvieron modificaciones pequeñas.

Es notable y alarmante que la acción antrópica está haciendo desaparecer la vegetación natural de cerrado. Como se puede ver en el Cuadro $\mathrm{N}^{\circ} 2$, en periodo de solo dos años, los usos originales del suelo, como mata ciliar, campo hidrófilo y cerrado perdieron $2,2 \%$ de su extensión. 
Cuadro $\mathrm{N}^{\circ} 2$

Tendencias en el uso del suelo verificadas de 2002 a 2004

\begin{tabular}{|l|r|}
\hline \multicolumn{1}{|c|}{ Usos } & \\
\hline Reforestación & $+3,9 \%$ \\
Reforestación cortada & $-1,9 \%$ \\
Cultura anual & $-3,0 \%$ \\
Cultura perenne & $+1,3 \%$ \\
Cultura irrigada & $+0,4 \%$ \\
Pastaje & $+1,0 \%$ \\
Mata & $+0,5 \%$ \\
Mata ciliar & $-0,4 \%$ \\
Campo hidrófilo & $-1,5 \%$ \\
Lechos de agua & $+1-0 \%$ \\
Cerrado & $-0,3 \%$ \\
& 0 \\
\hline
\end{tabular}

Fuente: Elaboración propia en base a Giffoni $2005 a$ y $2005 b$.

El arroyo Piçarrão también está siendo frecuentado, ya hace algún tiempo, por la población de Araguari, en virtud de ser una de las áreas de ocio de mayor belleza de la región, muy visitada durante los fines de semana y días feriados. Actualmente, se observa cierta degradación del área, causada, principalmente, por la visita espontánea, predatoria y sin control, además de la ocupación y forma de uso del suelo en su alrededor.

El lugar ha sido escogido no solamente por el paisaje encontrado, sino también como un área de ocio, donde los visitantes pueden acampar, hacer picnic, pescar y bañarse en el arroyo.

La actual forma de utilización del arroyo viene lentamente depredando la vegetación natural, lo que en el futuro puede causar graves problemas al suelo, que queda desprotegido y susceptible ante la acción erosiva. El área no presenta mata ciliar alguna.

En la Figura $\mathrm{N}^{\circ} 4$ es posible observar que el área es utilizada como lugar de ocio público, y consecuentemente se desarrolla turismo sin la infraestructura adecuada. La destrucción de fauna y flora ocurre principalmente en función de la polución de las aguas, provocada por los visitantes. El exceso de personas en esas áreas naturales en los fines de semana contribuye a la desaparición de varias especies de animales y plantas, debido al pisoteo, colecta de plantas y flores, quema de árboles y vandalismo, entre otros. A veces, en un único fin de semana, se puede registrar la presencia de hasta 800 personas.

La actividad turística es, sin duda, una de las actividades económicas con mayor impacto ambiental, una vez que repercute directamente sobre el uso de los recursos naturales y culturales, que son, vía de regla, su principal factor de atracción.

Un productor de la región relató: "Tuve que trancar mi propiedad debido a la invasión de personas que visitan el arroyo en los días calientes de verano. Mi familia está imposibilitada de usar el arroyo, porque cuando el agua llega a mi propiedad ya está sucia".

Los impactos ambientales son visibles al visitante y son percibidos y sentidos por los productores del lugar, que se sienten degradados junto al medio ambiente, por el corte de árboles y la basura dejada por los visitantes. De acuerdo con las entrevistas, se constata que el mayor problema ocasionado por los visitantes del Piçarrão es la basura. Existe una preocupación, por parte de la Secretaría de Turismo, de intentar sanar ese problema en la región.

\section{El uso del agua para irrigación}

El mercado globalizado ha influenciado definitivamente la actividad agropecuaria, una vez que el consumidor se hizo más exigente en relación a la calidad de los productos, especialmente los alimentarios. En función de eso, el grado de tecnificación de los productores de la cuenca del Piçarrão ha mejorado cada año; han invertido en nuevos sistemas de conducción de las plantaciones, utilizando las prácticas de irrigación, lo que demuestra el interés de los productores por garantizar mayor productividad y calidad.

La irrigación (Cuadro $N^{\circ} 3$ ) es la práctica que mejor caracteriza el uso de tecnología, 
Figura $\mathrm{N}^{\circ} 4$

Espacios de ocio en la cuenca

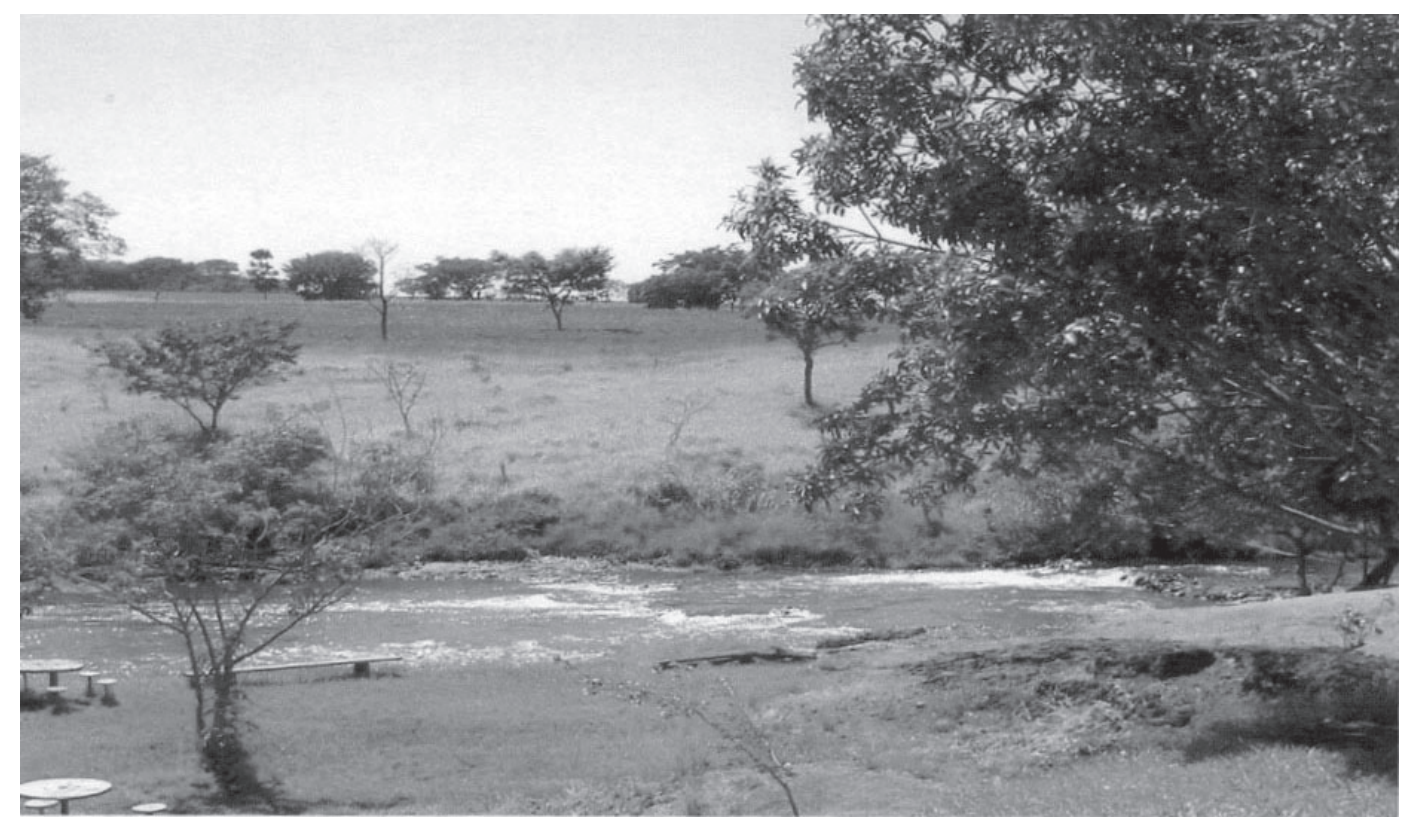

Fuente: Colección personal de los autores.

adoptada por $62,5 \%$ de los establecimientos investigados, entre los cuales $37,5 \%$ utilizan la irrigación por goteo, $12,5 \%$ por tripa y $6,25 \%$ de los entrevistados utilizan el pivote central. Entre los productores entrevistados, $12,5 \%$ utilizan en sus propiedades pivotes y goteo y $31,25 \%$ no irrigan sus tierras. De acuerdo con el mapa de uso del suelo, fueron identificados nueve pivotes en la cuenca del arroyo Piçarrão.

\section{Cuadro $\mathrm{N}^{\circ} 3$}

Tipos de irrigación usados en la cuenca

\begin{tabular}{|l|c|}
\hline Tipo de irrigación & $\%$ \\
\hline Pivote central & 6,25 \\
Goteo & 37,5 \\
Tripa & 12,5 \\
Pivote y goteo & 12,5 \\
Sin irrigación & 31,25 \\
\hline
\end{tabular}

Fuente: Elaboración propia.
La presencia controlada de agua en la producción agrícola, mediante el uso de irrigación, permite al agricultor, acostumbrado tradicionalmente a cosechar una zafra por año (época de las lluvias), ampliar el número de zafras, pasar a cultivar en diferentes estaciones y tener la posibilidad de cosechar varias veces al año. Ese tipo de cultivo puede mejorar el lucro de la producción por la remuneración extra que se obtiene, colocando el producto en el mercado en el momento de escasez del mismo. Según declaraciones de dos entrevistados: "Sin irrigación no se consigue cosechar nada en la entrezafra y el hecho de no disponer de la irrigación inviabiliza la café-cultura debido a las oscilaciones climáticas".

Aun sobre la irrigación es válido registrar las declaraciones de tres entrevistados que plantearon que si no se irriga no se produce. Uno de ellos declaró que todos los que puedan utilizar el agua para irrigación, la van a utilizar para aumentar la productividad, y otros dos mencionaron que hay que aprovechar bien la irrigación para gastar menos agua. 
De la muestra, el $25 \%$ de los entrevistados pretenden ampliar el área irrigada el próximo año y $75 \%$ no tienen la intención. Uno de los productores declaró, respecto de su propiedad, que varios pozos fueron desactivados por motivo de la mudanza del cultivo de café para soja y 340.000 pies de café fueron retirados para plantar soja.

El recurso de la irrigación es el agua, y como la competencia con otros sectores crece rápidamente, la propia agua podrá volverse el principal factor limitante para el desarrollo de la irrigación. Considerando la cuestión ambiental, la legislación se establece con el objetivo de reglamentar el uso de los recursos hídricos por los usuarios y de establecer instrumentos de gerencia, como la otorga de uso del agua y la cobranza por la utilización de los recursos hídricos (Brasil, 1997; Gobbi, 2002). Al respecto, los productores entrevistados, de la cuenca del Piçarrão, declararon que poseen la otorga del agua utilizada para irrigación.

De acuerdo con información adquirida por medio de una entrevista con el ingeniero proyector de otorgas de la empresa responsable en 2006, el área total drenada de la cuenca del arroyo Piçarrão es de 388 $\mathrm{km}^{2}$. El caudal mínimo es de $1.500 \mathrm{l} / \mathrm{s}$, el promedio es de $8.000 \mathrm{l} / \mathrm{s}$, y el máximo es de 80.000 l/s. Según declaraciones del ingeniero, toda la cuenca, en general, tiene un gran potencial de agua subterránea. El agua utilizada para irrigación no viene toda del arroyo, se utiliza mucha agua subterránea. Si retirasen solamente agua de los arroyos, no bastaría para irrigar toda la cuenca. Los arroyos Pindaituba y Lajeado ya alcanzaron su límite y no comportan un aumento del área irrigada.

\section{Los impactos del uso del suelo y del agua sobre el futuro de la cuenca}

Los impactos ambientales presentes en la cuenca del arroyo Piçarrão están relacionados con un conjunto de factores internos y externos del sistema socioeconómico, como el tipo de ocupación y manejo de suelo y el cumplimiento o no de las legislaciones ambientales (Dias, 1992; Ehlers, 1999; Novaes, 1993).
La soja es una cultura responsable por diversos impactos ambientales. Abonos son intensivamente aplicados en $80 \%$ de sus plantaciones, lo que hace de esa cultura una gran consumidora de agroquímicos (mitad del mercado nacional de herbicidas). La sojicultura es también gran usuaria de máquinas agrícolas, lo que ocasiona el aumento de la erosión y de la degradación de los suelos (Graziano, 1982; Graziano, 1986).

La utilización no planeada de la irrigación también perjudica a la naturaleza, pudiendo ocurrir el agotamiento de los recursos hídricos debido al uso indiscriminado de las fuentes, además de la destrucción de los ecosistemas de las márgenes de los arroyos.

El apresamiento y el desvío del curso de los arroyos disminuyen el volumen de agua disponible en áreas próximas de su lecho original, perjudicando otros hacienderos que de ellos se abastecen.

El uso indiscriminado de defensivos acarrea la contaminación del agua, del suelo y del ambiente natural en general, además del hecho de que los efectos a largo plazo del uso de altas concentraciones de correctivos y fertilizantes en el suelo, son poco conocidos.

Otro grave impacto del uso de defensivos es el empobrecimiento de los ecosistemas en especies nativas $y$, posteriormente, la posibilidad de aparición de plagas y la diseminación de malas hierbas.

De acuerdo con las entrevistas, se percibe que algunos productores no tienen reserva ecológica en las propiedades porque el precio de la tierra es alto. En ese sentido, sería económicamente inviable dejar que las áreas de reservas se regenerasen.

Según declaraciones de uno de los productores entrevistados en el trabajo de campo: "sembré mata ciliar, porque no había. La reserva es fuera de la hacienda y la discusión de comprar reserva fuera de la ciudad surgió con la experiencia de otra hacienda". 


\section{Consideraciones finales}

Con este trabajo fue posible identificar que el arroyo Piçarrão es palco de varias transformaciones que se deben a la modernización de la agricultura. Los productores buscan obtener mayor productividad y competitividad con la sustitución de la mano de obra por la máquina, con el uso de la irrigación y con la utilización de insumos producidos por el sector no agrícola.

Se constató en la cuenca que la mecanización de las plantaciones se muestra fuerte, con la introducción de nueve pivotes. La cuenca como un todo muestra un aumento del área irrigada porque tiene un gran potencial de agua subterránea, mas los arroyos Lajeado y Pindaituba no soportan ese aumento del área irrigada, pues ya alcanzaron su límite de suministro. El agua utilizada para irrigación es captada en el arroyo y sus afluentes, y también se utiliza agua subterránea.

Previendo el crecimiento del área irrigada en la cuenca del Piçarrão, el estudio mostró que las fuentes de agua son un factor limitante.

Haciendo un análisis general de cómo se presenta la ocupación del área estudiada respecto de mantener áreas de preservación, es preocupante el hecho de que, en toda la cuenca, existan pequeñas manchas de cerrado, que son difícilmente encontradas. Hay pocas áreas de preservación en el lugar, principalmente a lo largo del curso del arroyo Piçarrão, determinado por ley como una APP (Área de Preservación Permanente).

Las principales mudanzas verificadas en la cuenca de 2002 a 2004 fueron el aumento de la reforestación, de la cultura perenne, de la cultura irrigada y del pastaje, que juntas ocuparon $4,7 \%$ más de terreno. Este aumento significó la disminución de la cultura anual, de la mata ciliar, del campo hidrófilo y del cerrado. Aunque la reforestación sea un factor positivo, la disminución del área original de la mata ciliar, del cerrado y del campo hidrófilo es un factor negativo y necesita ser controlado.

\section{Referencias bibliográficas}

ASSUNÇÃO, W. L. Climatologia da cafeicultura irrigada no município de Araguari (MG). Tese doutorado em Geografia. Presidente Prudente: UNESP, Brasil, 2002.

BRASIL. Ley $N^{\circ}$ 9.433, de 8 de enero de 1997. Diario Oficial da União, Brasília, 9 jan, 1997.

BRUM, A. J. A Revolução verde. In: Modernização da agricultura: trigo e soja. Petrópolis: Vozes, ljuí, FIDENE, 1987, p. 44-50.

CHAGAS, L. A. C. Reflorestamento, políticas e incentivos fiscais no Triângulo Mineiro/AltoParanaíba. Uberlândia: Instituto de Geografia da UFU, 2002.

CUNHA, A. S. Uma avaliação da sustentabilidade da Agricultura nos cerrados. Estudos de Políticas Agrícolas, 1994, vol.13, № 23, p. 110-120.

DIAS, B. F. Alternativas de desenvolvimento dos cerrados. Brasília: Ibama, 1992.

EHLERS, E. Agricultura sustentável: origens e perspectivas de um novo paradigma. 2ª ed. Guaíba: Agropecuária, 1999.

FERREIRA, I. M. Bioma cerrado impactos e perspectivas ambientais. Quirinopólis: Anais do Simpósio de Geografia, VII EregeoGO, 2001.

GIFFONI, S. N. Composición colorida 3b4r7p, obtenida el 11/10/2002 del Satélite Landsat 7/ETNr, 2005a.

GIFFONI, S. N. Composición colorida 2b3p4r, obtenida del Satélite CBERS-2/CCD el 08/09/2004, 2005b.

GOBBI, W. A. Agricultura, meio ambiente e gestão das águas na Bacia do Rio Araguari (MG). Uberlândia: Instituto de Geografia da UFU, 2002.

GRAZIANO, F. Modernização da agricultura e questão agrária. In: Questão agrária e ecologia: crítica da moderna agricultura. $3^{\text {a }}$ ed. São Paulo: Brasiliense, 1986, p. 17-30. 
GRAZIANO, J. A modernização dolorosa: estrutura agrária, fronteira agrícola e trabalhadores rurais no Brasil. Rio de Janeiro: Zahar, 1982.

GRAZIANO, J. Modernização conservadora dos anos 70. In: Tecnologia e agricultura familiar. Pôrto Alegre: Editora da Universidade/ UFRGS, 1999, p. 87-135.

INSTITUTO BRASILEÑO DE GEOGRAFÍA ESTADÍSTICA (IBGE). Região do cerrado: uma caracterização do espaço rural. Rio de Janeiro: IBGE, 1979.

MARTINE, G. \& GARCIA, R. C. (Org.). Impactos sociais da modernização agrícola. São Paulo: Caetés, 1987.
NOVAES, M. Cerrado: caracterização, ocupação e perspectivas. $2^{a}$ ed. Brasília: Editora Universidade de Brasília, 1993.

PÊSSOA, V. \& SILVA, P. O café e a soja na (re) organização do espaço do Triângulo Mineiro/Alto Paranaíba. Uberlândia: UFU, 1999.

ROSA, R. Caracterização fisiográfica do município de Araguari. Sociedade \& Natureza, 1992, $\mathrm{N}^{\circ} 7$ e $\mathrm{N}^{\circ} 8$, p. 53-75.

SIQUEIRA, C. A. (Digitalizador). Base cartográfica Estado de Minas Gerais, Brasil Mapa geopolítico IGA 1994, 2005. 